\title{
ACTIVISMO DE ALTO RIESGO: EL FRENTE SANDINISTA DE LIBERACIÓN NACIONAL (FSLN) ¡PATRIA LIBRE O MORIR!
}

\author{
HIGH RISK ACTIVISM: THE SANDINISTA NATIONAL LIBERATION FRONT \\ (FSLN) ;PATRIA LIBRE O MORIR!
}

María Mercedes Salgado

Recibido: 31/05/2017 - Aceptado: 09/10/2017

\begin{abstract}
Resumen
El objetivo de esta investigación es explicar cómo se generó y desarrolló el activismo de alto riesgo del Frente Sandinista de Liberación Nacional (FSLN) de Nicaragua. Para ello se reconstruyen las oportunidades políticas para su surgimiento y las razones de la elección del repertorio de acción política violento en combinación con otro no violento; se examina el liderazgo de Carlos Fonseca y su rol angular en la construcción de los marcos interpretativos sandinistas que atrajeron a miles de jóvenes a movilizarse; y, finalmente, se reconstruye el perfil de los activistas, los factores que incidieron en ese tipo de compromiso, el reclutamiento en distintos contextos y coyunturas políticas. Para ello se utilizó un corpus de 121 entrevistas en profundidad de activistas del Frente Sandinista, dándoles un tratamiento cualitativo y estadístico descriptivo.
\end{abstract}

Palabras clave: Revolución Sandinista, revolución nicaragüense, movimientos sociales, activismo, Nicaragua.

\begin{abstract}
The objective of this research is to explain how the high-risk activism of the Sandinista National Liberation Front (FSLN) of Nicaragua was generated and developed. For this, the political opportunities for its emergence and the reasons for the choice of violent confrontation repertoire in combination with another non-violent one are reconstructed; the leadership of Carlos Fonseca and his angular role in the construction of Sandinist frameworks that attracted thousands of young people to mobilize are examined; and, finally, the profile of the activists is reconstructed, the factors that influenced that type of commitment, the volume and forms of recruitment according to different contexts of recruitment and political conjunctures. For this purpose, a corpus of 121 in-depth interviews of activists of the Sandinista Front was used, giving them a qualitative and descriptive statistical treatment.
\end{abstract}

Keywords: Sandinista revolution, Nicaraguan revolution, social movement, Activism, Nicaragua. 


\section{Introducción $^{1}$}

En julio de 1979, ríos de jóvenes llegaban a Managua, vestidos con uniformes verde olivo, levantando sus fusiles en señal de victoria. Eran activistas del conflicto armado que encabezó el Frente Sandinista de Liberación Nacional (FSLN) para derrocar a una de las dictaduras más largas y sangrientas del continente, la dinastía de la familia Somoza, e inaugurar la Revolución Popular Sandinista.

Si bien la Revolución Popular Sandinista y sus principales actores fueron objeto de estudio de varias corrientes teóricas, la lente poco se fijó en el interior del Frente Sandinista como un movimiento de alto riesgo. El ejercicio de reconstruir los antecedentes a nivel micro y meso del principal actor colectivo de la revolución nicaragüense, a la luz de una corriente teórica, permite sistematizar el conocimiento de un período de nuestra historia que cambió el destino de Nicaragua y Centroamérica. Representó el cambio del autoritarismo a la democracia, por muy de "baja intensidad" que ella sea en la actualidad (Torres-Rivas). En un escenario de exclusión, opresión y humillación de la mayoría de los nicaragüenses a lo largo de su historia, como expresan las narrativas de los activistas del movimiento sandinista, la única salida que quedó frente al gobierno somocista, apoyado por los Estados Unidos, fue la insurrección popular y el sacrificio de miles de sus ciudadanos.

Este estudio sobre el FSLN podría permitir comparaciones con el activismo de alto riesgo en otros países centroamericanos. Torres-Rivas destaca que la desobediencia popular en Guatemala, El Salvador y Nicaragua coincidió en el tiempo; sin embargo, no solo obedeció a causas diferentes, sino que también tuvo desarrollos diferentes. Goodwin coincide al señalar que dichos países con certeza son bastante similares y que es más que pura coincidencia que fuertes movimientos revolucionarios hayan surgido casi al mismo tiempo. No obstante, existen variaciones importantes en la política y en los resultados de los movimientos revolucionarios en la región, las cuales necesitan ser explicados. En ese sentido, América Central es un verdadero laboratorio de estudios.

Los estudiosos de los movimientos de alto riesgo siempre encontraron dificultades para obtener informaciones, porque muchos de ellos han surgido en contextos no democráticos y se ven obligados a permanecer en la clandestinidad guardando medidas de seguridad que los obliga a apagar todo tipo de huellas. En ese sentido, las entrevistas realizadas por la comandante guerrillera del FSLN en su programa de radio Entre todos, entre 1999 y 2002, y luego transcritas en el libro Memorias de la lucha sandinista, después de haberles dado tratamiento de historia oral, es un material de entrañable valor. Se tomó como base empírica para este estudio 121 entrevistas en profundidad, de 102 activistas y 19 colaboradores del Frente Sandinista, a las que se les dio un tratamiento cualitativo de análisis de contenido y estadístico descriptivo. 
En un país con altos niveles represivos, instituciones políticas frágiles y movimientos sociales insignificantes, ¿cómo el Frente Sandinista logró construir una identidad nueva y relevante?, ¿de qué forma se produjo el compromiso de tantos y tantas jóvenes que arriesgaron sus vidas en una carrera peligrosa y costosa, muchas veces sin vuelta?, ¿cuál es su perfil? y ¿dónde y cuándo fueron reclutados?

En la primera parte del artículo se reconstruyen las oportunidades políticas para la movilización del ciclo de protestas 1958-1963 que son los antecedentes políticos del FSLN. Se hace una sistematización de los movimientos armados y de resistencia civil y se explica cómo el FSLN se constituye en un movimiento de alto riesgo.

En la segunda parte se hace referencia al tipo de liderazgo de Carlos Fonseca y su rol fundamental en la construcción del marco interpretativo "sandinismo", sus influencias culturales más significativas, Sandino y la Revolución Cubana, y como el sandinismo y el cristianismo se amalgamaron favoreciendo el reclutamiento de tantos jóvenes.

En la tercera parte se reconstruye el perfil sociodemográfico de los activistas y los factores individuales y vínculos sociales que favorecieron su identificación con los marcos interpretativos sandinistas, los contextos en que fueron reclutados y como varió el reclutamiento en distintas coyunturas políticas.

\section{Antecedentes y oportunidades para el activismo de alto riesgo}

\section{Creando oportunidades políticas para el activismo de alto riesgo ${ }^{2}$}

Anastasio Somoza García inició una nueva campaña política en 1956 como candidato a su tercer mandato por del Partido Liberal. Ante esta posibilidad, un grupo de opositores, entre ellos Edwin Castro y Rigoberto López Pérez, llegó a la conclusión de que no había otra salida que "ajusticiarlo", lo cual sería un símbolo del repudio y una forma de despertar a las fuerzas progresistas y revolucionarias, del largo letargo en que estaban sumergidas (Baltodano, 2010).

López se encargó voluntariamente de ejecutar la acción planeada el 21 de septiembre de 1956, mientras Castro y tres activistas más permanecían en la retaguardia. Ante la disposición de Somoza de salir más temprano del lugar, López decidió dispararle sin ninguna posibilidad de salir vivo. Su cuerpo fue acribillado a balazos por la Guardia Nacional (GN), desapareciendo para siempre. En la carta que dejó a su madre explicaba que todos los esfuerzos habían sido inútiles para que Nicaragua fuera "una patria libre, sin afrentas y sin manchas, y que había decidido "tratar de ser yo el que inicie el principio del fin de esa tiranía" (Fonseca 398).

Somoza García murió días más tarde. Centenas de ciudadanas y ciudadanos opositores al régimen y otros sin actividades políticas conocidas, cayeron presos, entre 
ellos, Carlos Fonseca y Tomás Borge, fundadores del FSLN, y Pedro Joaquín Chamorro, editor del diario La Prensa, propiedad de su familia. Castro y sus compañeros fueron cruelmente torturados y finalmente asesinados en 1960.

El concepto de estructura de oportunidades políticas $(\mathrm{EOP})^{3}$ es útil para explicar cómo en una situación de restricción de oportunidades políticas, los activistas logran romper el bloqueo y crear oportunidades para la movilización colectiva. Sin embargo, como explican Para McAdam, Tarrow y Tilly, ninguna oportunidad que se abre objetivamente invita a la movilización si no es visible para los potenciales desafiadores, y percibida como tal. Por su parte, la represión sistemática a los insurgentes y la falta de canales regulares de expresión transforman a disidentes moderados en opositores que se plantean el problema de destituir al gobierno como condición para efectuar cambios (Tarrow).

El asesinato de Somoza García es la acción practicada por opositores para crear oportunidades políticas para otros movimientos. Así lo interpretaron aquellos que se movilizaron como Carlos Fonseca:

En 1956, la lucidez que da la vergüenza permite a Rigoberto prestar atención al hecho más notorio: (Anastasio Somoza) ha sobrevivido por más de veinte años, asesinando, saqueando, traficando la soberanía... Solo dos años después de 1956, empuñan de nuevo el fusil guerrillero supervivientes veteranos del ejército de Sandino, encabezados por el anciano Ramón Raudales... Y cinco años más tarde... se integra la fuerza revolucionaria que procede a denominarse Frente Sandinista de Liberación Nacional, FSLN (Fonseca 392-393).

La acción de los opositores y sus consecuencias -represión indiscriminada y frustración por la prolongación del régimen somocista- son los eventos que impulsaron las primeras acciones armadas y de resistencia civil en las que participaron veteranos sandinistas, ex oficiales de la Guardia (GN) y activistas del movimiento estudiantil y de los partidos políticos.

Estos movimientos se difundieron con mucha velocidad hasta alcanzar su ápice en 1959, agotándose en 1963, y conformaron lo que Tarrow define como un ciclo de protestas, un período de confrontación en el sistema social en el que la acción colectiva se difunde rápidamente, con innovadoras formas de confrontación, nuevos marcos de referencia y secuencias de interacción entre disidentes y autoridades que pueden terminar en reforma, represión, y a veces en revolución.

Las oportunidades políticas se abrieron para las movilizaciones del ciclo de protestas y para un tipo específico de acción política: la guerrilla.

\section{La difusión del repertorio cubano y la opción por la guerrilla}

Desde 1956 el movimiento cubano 26 de Julio (M-26-7) de Fidel Castro y Che Guevara obtenía victorias contra la dictadura de Fulgencio Batista y el fulcro de su 
repertorio de confrontación ${ }^{4}$ era la lucha armada. El mismo repertorio había sido utilizado por Augusto C. Sandino ${ }^{5}$ y su Ejército de Defensa de la Soberanía Nacional de Nicaragua (EDSN) en la guerra contra la ocupación norteamericana. Hodges recuerda que antes de la guerrilla de la Sierra Maestra, Fidel Castro buscó al coronel cubano Alberto Bayo, exiliado en la ciudad de México, para solicitar entrenamiento militar para los activistas del M-26-7. La estrategia militar de Sandino sobrevivió gracias a los esfuerzos de Bayo que escuchó las historias contadas por los sobrevivientes del EDSN y las incorporo a su manual sobre las guerrillas, 150 Questions for a Guerrilla, grabándolas en el M-26-7. Así, Bayo fue la conexión entre la experiencia de Sandino y la experiencia de la Revolución Cubana, y como se verá, el Che será la conexión con los insurgentes nicaragüenses.

Los exiliados nicaragüenses, el sector más movilizado contra la dictadura que se congregaba en los países vecinos, fueron los primeros en percibir las oportunidades creadas por el asesinato de Somoza García y el avance de la guerrilla cubana. El general Ramón Raudales, veterano sandinista, y sus compañeros constituyeron la jefatura militar de la nueva guerrilla. También se alistaron varios estudiantes procedentes de Honduras, El Salvador, Guatemala y México (aproximadamente 25 hombres en total).

La derrota de Raudales en octubre de 1958 no desanimó a los insurgentes, pero fue el triunfo del M-26-7 y la inauguración de la Revolución Cubana lo que les infundió renovados ánimos de combate contra la dictadura somocista. "El año de 1959 fue el más violento de la era somocista, antes de 1978" (Blandón 82). Invasiones del Sur y del Norte, agitación estudiantil y protestas generalizadas ocurrieron aquel año.

En Nicaragua Hora Zero, Fonseca afirma que, desde el asesinato de Sandino en 1934, hasta el triunfo de la Revolución Cubana en 1959, la lucha armada fue interrumpida en Nicaragua como táctica sistemática de combate al régimen, predominando en el liderazgo de la oposición sectores del Partido Conservador. "La rebelión del pueblo cubano influyó aún antes de culminar victoriosamente" (Fonseca 159) en la guerrilla de Raudales y en todas las otras que se produjeron hasta finales de la década de 60. Borge escribió que "la victoria de la lucha armada en Cuba más que una alegría, fue la apertura de incontables cortinas... Fidel fue para nosotros la resurrección de Sandino, la respuesta a nuestras dudas" (Borge 22).

La difusión del repertorio contencioso cubano tuvo su momento en 1959. Los primeros movimientos son clústeres de nuevos productos culturales -nuevos marcos cognitivos, rutinas de comportamiento, formas de organización, repertorios tácticosy están sujetos a los mismos mecanismos de diseminación de otras innovaciones, es decir, a través de las estructuras de redes que funcionan cotidianamente en la vida social (McAdam). Los activistas nicaragüenses reconocieron las similitudes entre los gobiernos de Somoza y Batista: ambos surgieron de golpes militares contra sus aliados, sostenidos por la incondicional ayuda de Estados Unidos y hábiles para aplastar cualquier intento de rebelión. Por eso, creyeron que las condiciones 
para desarrollar movimientos insurreccionales eran obvias, y debían aceptar la invitación del gobierno cubano a participar en esa tarea. Una heterogénea colonia de nicaragüenses se presentó en La Habana, proveniente de Nicaragua y de varios países centroamericanos (Blandón).

A partir de ese momento los movimientos armados se multiplicaron en Nicaragua. Algunos recibieron el apoyo directo del Che Guevara, especialmente la guerrilla de El Chaparral, la Columna 15 de Septiembre y el Frente Revolucionario Sandino (Baltodano, volumen 1). Los activistas que sobrevivían a la derrota de un movimiento, rápidamente se comprometían en otro. También los miembros del partido conservador irrumpieron en Nicaragua desde la vecina Costa Rica, esto confirma la tendencia de los sectores menos movilizados a usar el repertorio de los más movilizados durante los ciclos de protesta (Tarrow). La Tabla 1 exhibe las iniciativas armadas del ciclo de protestas.

Tabla 1

MOVIMIENTOS ARMADOS DEL CICLO DE PROTESTAS

\begin{tabular}{llc}
\hline Movimientos & Duración & $\begin{array}{c}\text { Número de } \\
\text { activistas }\end{array}$ \\
\hline Guerrilla del general Ramón Raudales & Septiembre/Octubre 1958 & 41 \\
Desembarque Olama y Mollejones & Mayo/Junio 1959 & 65 \\
Guerrilla de El Chaparral & Junio 1959 & 55 \\
Guerrilla de Chale Haslam & Junio/Noviembre 1959 & S. d. \\
Columna Augusto C. Sandino & Julio/Agosto & 22 \\
Frente Revolucionario Sandino & Noviembre 1959/Diciembre 1960 & S. d. \\
Guerrilla de Heriberto Reyes & Diciembre 1959 & 25 \\
Columna 15 de Septiembre & Septiembre/Diciembre 1960 & 50 \\
Movimiento 11 de Noviembre & Noviembre 1960 & 40 \\
Guerrilla Raití-Bocay/Frente de Liberación Nacional & Julio 1963 & 63 \\
\hline
\end{tabular}

Fuente: Elaboración propia a partir de Baltodano y Blandón.

Como parte del ciclo de protestas hubo iniciativas de resistencia civil en las principales ciudades. En esa coyuntura se constituyó otro actor colectivo relevante: el 
movimiento estudiantil, que se animó con la victoria del M-26-7 y se indignó con la represión a los movimientos guerrilleros, enfrentando a la GN en manifestaciones callejeras. Algunos de esos activistas participaron también en las iniciativas guerrilleras. La Tabla 2 exhibe dichas iniciativas.

Tabla 2

LA RESISTENCIA CIVIL DEL CICLO DE PROTESTAS

\begin{tabular}{lc} 
Movimientos & Fecha \\
\hline Generación del 23 de Julio & 1959 \\
$\begin{array}{l}\text { Unión Nacional Opositora (UNO): coalición de los partidos PLI, PSCN, Partido } \\
\text { Renovación Nacional y Partido Movilización Republicana, encabezada por el Partido } \\
\text { Conservador. }\end{array}$ & 1959 \\
$\begin{array}{l}\text { Juventud Democrática Nicaragüense (JDN) } \\
\text { Frente Revolucionario Nicaragüense (FRN) }\end{array}$ & 1959 \\
Frente Unitario Nicaragüense (FUN) & 1959 \\
Juventud Patriótica Nicaragüense (JPN) & 1960 \\
Movimiento Nueva Nicaragua (MNN) & 1961 \\
Frente Estudiantil Revolucionario (FER) & 1962
\end{tabular}

Fuente: Elaboración propia a partir de Baltodano y Blandón.

Blandón (1980) destaca que la novedad en 1959 fue el surgimiento de movimientos ubicados más a la izquierda del espectro político. La hegemonía conservadora se vino reduciendo cuando entró en escena la guerrilla de Raudales y el triunfo de la Revolución Cubana, la que "produjo un tremendo impacto en el movimiento opositor nicaragüense, polarizando las fuerzas y dejando claras diferencias entre los movimientos progresistas y los partidos tradicionales" (Blandón 83). Surge un nuevo tipo de oposición formada por una generación más joven, más radical, que se identificaba con la Revolución Cubana, con la campaña antiimperialista de Sandino y con un programa de libertades democráticas. 
Pese a las derrotas y muerte de un gran número de activistas, para Fonseca y sus compañeros esos años proporcionaron una arena muy amplia para las actividades políticas y reclutamiento de partidarios (Zimmermann). Esos movimientos son los “antecedentes más visibles del FSLN" (Borge 130). Fonseca insistirá en agregar el término "sandinista" al Frente de Liberación Nacional (FLN), último movimiento armado del ciclo de protestas, lo que finalmente ocurrirá en 1963.

\section{Cambios en las oportunidades políticas, desmovilización y repertorio violento del FSLN}

A principios de 1963, el ciclo de protestas comenzó a declinar. Contribuyó para ello la decisión de Luis Somoza de no reelegirse, nombrando a su ministro de educación, René Schick, candidato del Partido Liberal. Esto produjo en la oposición moderada la esperanza de un cambio democrático por la vía electoral y causó el decaimiento del activismo político más radical. Gracias a una amnistía política concedida por Schick, los opositores radicados en el exterior lograron volver a sus actividades en Nicaragua.

Hubo un repunte de la oposición moderada después que Schick murió repentinamente en 1966, y esta se dispuso a disputar las elecciones con Somoza Debayle. Sin embargo, durante la manifestación multitudinaria de cierre de campaña el 22 de enero de 1967, la GN disparó contra la multitud dejando centenas de muertos, heridos y presos.

Dicha masacre aunada a la perpetuación en el poder de la familia Somoza confirmaron para el FSLN que la estrategia de lucha armada era la principal performance política para derrocar a la dinastía dentro de un contexto de más amenazas que oportunidades para la acción política. La guerra de guerrillas formaba parte del repertorio contencioso que permanecía disponible para ellos, el mismo que había sido usado por Sandino y los revolucionarios cubanos. Así lo expresó Fonseca:

La insurrección popular armada es la médula de la lucha contra la dictadura. La lucha, de acuerdo a las circunstancias geográficas de nuestro país y de la gran fuerza material del ejército de la dictadura, tendrá que ser de tipo guerrillero, tipo que tantas victorias produjo al glorioso general Augusto César Sandino, cuando combatía en las Segovias contra la infantería de marina de Estados Unidos de Norteamérica. La lucha sandinista en definitiva demostró que nuestro pueblo puede librar victoriosas batallas contra enemigos muy poderosos materialmente (Fonseca 112-113).

Al mismo tiempo, la violencia, como medio de resolución de conflictos políticos, estaba en el entramado de la cultura política nicaragüense. Ramírez menciona que uno de los países centroamericanos que más tuvo guerras civiles después de la independencia de España fue Nicaragua. Los liberales se instalaron en León y los conservadores en Granada, donde cada grupo organizó la vida económica y política independiente del 
otro, y desde donde arrastraban a los campesinos al torbellino de las guerras civiles. Kinloch Tijerino se refiere a este período como de anarquía.

A principios del siglo XX, tras una fase de relativa calma, sobrevino la ocupación militar norteamericana. Atendiendo llamados de los bandos en disputa, y de acuerdo a sus intereses, el gobierno de los Estados Unidos mantuvo a los fusileros navales de 1912 a 1933, con un breve intervalo. A esas disputas intestinas se refería Fonseca en 1970 cuando respondió a la pregunta de un periodista sobre la validez de su experiencia guerrillera:

En Nicaragua no hay que pensar mucho para convencerse que el camino armado es el único viable. Ya en aquel momento podiamos ver que en la historia de nuestro país ni siquiera los dos bandos oligárquicos surgidos de la independencia de España pudieron relevarse alguna vez de forma pacífica en el poder. Siempre lo hicieron por la fuerza de las armas. Entonces ¿qué esperanza en un camino pacífico podía tener un movimiento revolucionario? (Fonseca 292).

El enfrentamiento de guerrillas en las montañas fue la forma de acción violenta más utilizada por el FSLN, de 1963 a 1977, con interrupciones después de las derrotas. A partir de 1977, el escenario de las acciones violentas se trasladó a las ciudades y la insurrección popular se convirtió en la principal performance de acción política.

Durante su trayectoria, el FSLN utilizó otras performances como asaltos a bancos para autofinanciamiento; asesinato de represores, "orejas" (informantes) y jueces de mesta (coadyuvantes de la represión de la GN en las montañas); secuestros de aviones para rescate de presos políticos; ocupaciones de locales para secuestro de rehenes con el objetivo de divulgar posicionamientos políticos, rescatar presos políticos y obtener dinero para autofinanciamiento.

Del ciclo de protestas surge el Frente Sandinista que, después de las primeras experiencias guerrilleras, comprendió que el proceso de derrocada de la dictadura sería prolongado y difícil y que era necesario, en las palabras de uno de sus primeros activistas, Víctor Tirado:

Establecer un organismo politico con un programa, una táctica y una estrategia propias, que fuera capaz de dar continuidad a la lucha armada y de trabajar en todas las circunstancias: en la clandestinidad, en la semiclandestinidad o abiertamente... que señalara y probara en la práctica que la lucha armada era la vía principal para derrocar a la dictadura y para transformar radicalmente a Nicaragua...Pero no era la única. Porque si nos dedicáramos única y exclusivamente a preparar acciones armadas y descuidáramos otras formas de lucha... corríamos el riesgo de convertirnos en una secta (Tirado 40-42).

Efectivamente, el FSLN le dio impulso y orientación política al movimiento estudiantil por medio del Frente Estudiantil Revolucionario (FER), integró a los activistas 
del Movimiento Cristiano Revolucionario (MCR) y organizó la Asociación de Mujeres ante la Problemática Nacional (AMPRONAC), la Asociación de Trabajadores del Campo (ATC) y los Comités de Defensa Civil (CDC). Hizo uso de performances no violentas como manifestaciones, huelgas, huelgas de hambre, ocupaciones de iglesias y colegios, actos litúrgicos, teatro y festivales de la canción, entre otras.

\section{El liderazgo y los marcos interpretativos del sandinismo}

\section{El liderazgo de Carlos Fonseca}

Para que el activismo de alto riesgo se constituya, son necesarias, además de las oportunidades políticas para la acción, un liderazgo capaz de amalgamar recursos y adeptos para este tipo de actuación política y la difusión entre activistas y simpatizantes de una creencia en la relevancia y pertinencia de esa forma de acción.

Diferentes teorías sobre los movimientos sociales han identificado dos tipos de liderazgo: task-oriented y people-oriented. El primero orientado a la organización de recursos y acciones para alcanzar un objetivo determinado. El segundo, carismático, evoca un estado de motivación y compromiso, y a menudo de identificación con el líder o su movimiento (Aminzade et al.). Aquí se argumenta que Fonseca reunía los dos atributos. Como líder de organización.

Durante unos 20 años, Fonseca fue la figura ideológica central y el líder estratégico del movimiento revolucionario en Nicaragua. ...Hasta su muerte, Carlos Fonseca desempeñó, incluso en la prisión o en el exilio, un papel crucial en la organización del trabajo diario del FSLN, reclutando cuadros, expandiendo la influencia politica y planificando sus operaciones militares (Zimmermann 8).

Como líder carismático, “Carlos Fonseca, aunque ya no estaba vivo, era el héroe popular de la revolución nicaragüense de 1979. Era mucho más conocido por el ciudadano común que cualquiera de las personas que formaban el nuevo gobierno revolucionario" (Zimmermann 8). Borge se refiere a Fonseca como "el principal fundador de nuestros sueños, el jefe, de una vez y para siempre, del Frente Sandinista de Liberación Nacional (Borge 138).

Los actores de los movimientos sociales construyen significados (framing processes) para sus colegas, antagonistas, partidarios y observadores mediante la elaboración de marcos interpretativos. Sirven para identificar un problema y asignar de quién es la culpa o cuál es la causa; sugieren estrategias, tácticas y metas para solucionarlo; y construyen un llamado a las armas o justificación para la acción (Snow y Benford). 
La contribución de Fonseca fue relevante en la configuración de una creencia colectiva, el marco interpretativo sandinismo, que permitió al movimiento ir edificando su identidad y obtener adhesión popular. Como se verá, dicho marco se originó de la conjunción de otros dos: el nacionalismo antiimperialista de Sandino y el marxismo revolucionario de la Revolución Cubana, creados durante sus ciclos de protestas como elementos culturales que el FSLN tomó para construir su propio marco de acción colectiva.

\section{La difusión del marco interpretativo nacionalista y antiimperialista de Sandino}

Bajo la influencia de la Revolución cubana Carlos Fonseca advirtió que para hacer una revolución victoriosa era necesario algo más que el modelo estándar de la teoría y la estrategia marxista-leninista. Sin raíces nacionales y una ideología popular, el marxismo se convertiría en una secta política. Fonseca entonces se impuso la tarea de reinterpretar el pensamiento de Sandino que sería el vehículo del marxismo-leninismo en Nicaragua (Hodges).

Sandino, de acuerdo con Girardi, se orientaba por una visión profética o utópica que contenía tres elementos: la soberanía nacional, el latino-americanismo y el internacionalismo. Estimulado por esa utopía, desarrolló un análisis objetivo y una estrategia eficaz para transformar la realidad. No se podía contar con las oligarquías nacionales en la conquista de la soberanía nacional, solo con los obreros y campesinos, protagonistas principales de su proyecto al que podían adherir todos los que defendieran la soberanía nacional. La utopía se hacía realidad al adoptar la estrategia de la lucha armada como el único camino concreto de combate popular. La liberación de los oprimidos y la capacidad del pueblo de entregarse a esa causa le daban a Sandino la certeza del triunfo.

Desde 1956 Fonseca se dedicaba al rescate de la experiencia de Sandino. Para él, el movimiento de Sandino estaba inscrito en una larga tradición de resistencia de las masas explotadas de Nicaragua, que con sus éxitos militares y su embrionario programa de cambios sociales había logrado elevar la lucha a otro nivel (Hodges; Zimmermann). El papel histórico del FSLN era cumplir las tareas que Sandino no había concluido,

guiando a los trabajadores y campesinos nicaragüenses hacia la victoria contra el imperialismo y sus representantes locales, e impulsar un programa de profundos cambios sociales.

Además del conocimiento escrito de Sandino, en 1963 Fonseca fue en búsqueda de un veterano de su guerrilla, el coronel Santos López, quien aceptó participar en la guerrilla que Fonseca y sus compañeros estaban organizando. Sobre ese encuentro Borge escribió: "Se juntan, de este modo, dos generaciones de nicaragüenses sellados por la presencia histórica del pensamiento sandinista... Los viejos sandinistas nos transmitieron sus experiencias que cayeron en un terreno hambriento de semillas y nuevas perspectivas" (Borge 27). 
Se trata aquí, pues, de la difusión del marco nacionalismo antiimperialista que Sandino fue construyendo durante las batallas contra los infantes de marina norteamericanos. En su primer manifiesto político del 1. ${ }^{\circ}$ de julio de 1927, se lee la consigna PATRIA Y LIBERTAD, que desde entonces figurará al pie de todos sus documentos; adoptó la bandera rojinegra con la inscripción LIBERTAD O MUERTE y el pañuelo rojinegro atado al cuello.

Mediante relaciones interpersonales de confianza y comunicación regular, las lecciones de Sandino llegaron al coronel Bayo, que las compartió con los miembros del M-26-7. El Che Guevara, a su vez, se encargó de transmitirlas a los primeros movimientos del ciclo de protestas nicaragüense después del triunfo da la Revolución Cubana. Fonseca, que ya había percibido la importancia de Sandino, reinterpretó su pensamiento incorporándolo al FSLN al igual que la experiencia viva en la persona del coronel Santos López.

\section{La difusión del marco interpretativo marxismo revolucionario de la Revolución cubana}

El FSLN también recibió el impacto de la difusión de un segundo marco interpretativo: el marxismo revolucionario de la Revolución cubana.

Cuba desempeñó un papel fundamental en varios niveles, hecho confirmado por los estudios sobre los movimientos revolucionarios latinoamericanos (Lowy; Castañeda; Pereyra; Gaspar; Wright; Álvarez). ${ }^{6}$ De acuerdo con Wright, la vasta influencia de la Revolución cubana en América Latina se debió al hecho de que ella encarnó las aspiraciones y capturó la imaginación de la juventud latinoamericana como ningún otro acontecimiento revolucionario lo había hecho antes. ${ }^{7}$

El marco interpretativo marxismo revolucionario se difundió directamente por medio de un gran número de latinoamericanos que visitaron La Habana, la cual rápidamente se convirtió en la Meca revolucionaria donde potenciales guerrillas podían ser preparadas espiritual y materialmente para la contienda revolucionaria (WickamCrowley). Se propagó también indirectamente, por medio de los escritos del Che Guevara. Todos los movimientos guerrilleros después de esta fase pasaron por el mismo proceso de transformación en la forma de ver el mundo, incorporando la guerra de guerrillas a su repertorio cultural y rompiendo con los tradicionales partidos comunistas alineados con la Unión Soviética.

Fonseca, como militante del Partido Socialista Nicaragüense (PSN) se rehusó a regresar a Nicaragua después participar en la guerrilla del El Chaparral, uno de los movimientos armados del ciclo de protestas y escogió el nuevo marxismo-leninismo. Sandino y el Che Guevara fueron las dos figuras que más influyeron en su pensamiento (Fonseca).

Hodges resalta que para el nuevo marxismo-leninismo hacer la revolución era un imperativo moral de todo revolucionario. Las condiciones objetivas estaban 
dadas por el hambre del pueblo y la represión a lo largo de los siglos, lo que faltaba en América Latina eran las condiciones subjetivas, es decir, la conciencia de que era posible vencer al Estado, iniciando un conflicto armado. También desplazaron el eje de los principios del socialismo científico para los sentimientos y actitudes revolucionarias. Guevara defendía el carácter subjetivo del nuevo marxismo: un marxista no tiene que renunciar a los sentimientos humanos, a la camaradería, al amor por los hermanos. Es por amor a la humanidad que el revolucionario decide combatir la miseria, la injusticia, las aflicciones y la explotación del proletariado. Esta dimensión ideológica fue la base para la construcción de la doctrina del "hombre nuevo" de Guevara. Para triunfar, los guerrilleros debían tener una conducta moral intachable, practicando el autocontrol y la abnegación, y siendo ascetas.

Fonseca bebió de la fuente del nuevo marxismo del Che Guevara y Fidel Castro:

Adivino... una nueva época en las Américas. El movimiento glorioso del pueblo cubano encabezado por Fidel Castro y Ernesto Che Guevara, alumbró el camino de todos. Y a su luz surgió de nuevo en Nicaragua el esfuerzo que reanudaba el intento de la década del 30: el Frente Sandinista de Liberación Nacional habia nacido como fiel expresión de la decisión combativa de las nuevas generaciones nicaragüenses (Fonseca 362).

La difusión del marco marxismo revolucionario, condensado en la consigna "Patria o muerte venceremos", se difundió a través de relaciones interpersonales de confianza y comunicación regular de las redes de activistas nicaragüenses con los revolucionarios cubanos. Indirectamente también por medio de los escritos del Che Guevara y de los largos discursos de Fidel Castro.

\section{La construcción del marco interpretativo sandinista}

En Nicaragua el marco interpretativo marxismo revolucionario se enraizó en un movimiento nacional que terminó en una revolución victoriosa. "El sandinismo contemporáneo es la fusión del pensamiento marxista revolucionario con la herencia intelectual de Sandino"' (Hodges 173).

En el prólogo del libro de Fonseca Viva Sandino, Jaime Wheelock escribe que Fonseca se decidió por un ideario de Sandino porque las nuevas generaciones, conscientes de la deprimente situación económica y política de Nicaragua, requerían de las lecciones de moral, dignidad, patriotismo, de la ideología renacida de la lucha por da defensa de la soberanía nacional.

Zimmermann subraya que, en su reinterpretación del pensamiento de Sandino, Fonseca entendía que el imperialismo dominaba su país y una genuina independencia solo podía alcanzarse con el derrocamiento de Somoza Debayle. Esperaba convencer a sus coterráneos que una guerra contra el imperialismo no era ni imposible ni una locura 
siempre que tuvieran apoyo popular y un liderazgo dispuesto a combatir. A pesar de que en los años 70 ningún de marina de los Estados Unidos ocupaba Nicaragua, el FSLN combatía a la Guardia Nacional como un instrumento de la dominación de los Estados Unidos.

Los mencionados marcos interpretativos "Patria y libertad, libertad o muerte y patria o muerte venceremos" condensan la lucha por valores patrióticos, antiimperialistas y de defensa de la soberanía nacional. El FSLN adoptó el marco "Patria libre o morir", con el llamado a derrocar a la dictadura somocista y al imperialismo norteamericano. Fue extraído por Fonseca de una carta de Sandino a un oficial de la marina de los Estados Unidos que lo instaba a rendirse: "No me rendiré y aquí los espero. Yo quiero patria libre o morir" (Ramírez 149).

La bandera rojinegra con la inscripción FLSN y el pañuelo de los mismos colores atados al cuello o al rostro fueron la marca registrada de las acciones de propaganda armada durante la insurrección popular y los 10 años de revolución sandinista, y sobreviven hasta hoy como sus símbolos.

En la visión de Carlos Fonseca y el FSLN, la dinastía somocista y el apoyo que recibió de los Estados Unidos provocaron una situación de injusticia caracterizada por la miseria y el analfabetismo, la represión y falta de libertades democráticas, el enriquecimiento ilícito y la corrupción de los agentes del gobierno y de las élites asociadas. La solución señalada por los marcos sandinistas era la lucha armada para derrocar a la dictadura, al imperialismo, recuperar la soberanía nacional y fundar el socialismo.

\section{El marco interpretativo cristianismo revolucionario}

Hay tres grandes momentos en la historia de la participación de los cristianos en el proceso revolucionario nicaragüense, nos recuerda el pastor bautista, José Miguel Torres (Baltodano, 2010, tomo I). El primero, a partir de la Revolución Cubana el cristianismo es sensible a la entrega de personas de otra ideología y hubo grupos que formaron parte de la Juventud Universitaria Católica. El segundo momento es la década del setenta, después de la Conferencia de Medellín, en que hay una participación masiva de los cristianos a nivel de parroquias y cuentan con el apoyo de obispos del continente. El tercer momento es durante el proceso revolucionario cuando cientos de miles de cristianos participan de las organizaciones de masas, en los diferentes esfuerzos de defensa de la revolución.

Alrededor de 1966, Fonseca y Borge se acercaron al religioso Ernesto Cardenal. En aquel momento él acababa de fundar la comunidad cristiana de Solentiname en el archipiélago del lago Cocibolca, proyecto de renovación eclesial que a lo largo de 11 años de existencia se convirtió en una comunidad identificada con la lucha del FSLN. Las conversaciones, destaca su hermano Fernando Cardenal (Baltodano, tomo I), también sacerdote, giraban en torno a que el FSLN quería hacer una revolución popular 
de la que participara todo el pueblo, y el pueblo profesaba la fe católica. No se trataba, para Fonseca, que la gente se volviera atea sino revolucionaria. Para ello, los sacerdotes eran muy importantes.

En la Conferencia de Medellín en 1968, en que surge el pensamiento que comenzará a llamarse teología de la liberación, ${ }^{8}$ los cristianos abrazan la idea de que hay que "acompañar al pueblo en su proceso de liberación integral. Esto en Nicaragua se traduce por acompañar al pueblo en su proceso revolucionario sandinista" destaca Fernando Cardenal (Baltodano, tomo 1, 348).

Estas ideas impulsaron a sacerdotes, monjas, pastores y jóvenes cristianos dentro de un espíritu ecuménico (católicos, protestantes, evangélicos) a iniciar una labor de concientización, impulsando pastorales en las parroquias, seminarios, retiros espirituales, escuelas radiofónicas, el "Evangelio de Solentiname", el foco de reflexión teológica del Barrio Riguero, eventos de formación y clarificación ideológica donde se invitaba a dirigentes revolucionarios a hacer un análisis de la realidad nacional. Este fue el caso de Ricardo Morales Avilés, miembro de la dirección del FSLN y uno de sus ideólogos más importantes, que tenía una visión estratégica de la participación de los cristianos en el proceso revolucionario y reclutó a muchos de los activistas cristianos de la comunidad del Barrio Riguero. En septiembre de 1973, salió de una casa de retiros, donde se celebraba un encuentro latinoamericano de cristianos y donde planteó la necesidad de la lucha armada, hacia la muerte.

Además, los cristianos contribuyeron con nuevas performances de acción política: las tomas de iglesias y colegios y los ayunos. Así fue como el terremoto de diciembre de 1972 sorprendió a más de 100 personas que realizaban un ayuno profético en la Catedral de Managua.

Los activistas de los movimientos religiosos fueron incorporándose al FSLN de forma individual. El dirigente del Movimiento Cristiano Revolucionario (MCR), Luis Carrión, describe la situación en 1974: las comunidades eclesiales de base estaban diseminadas en los barrios con alto grado de politización, y a través de los vínculos con esas comunidades, los dirigentes cristianos las aproximamos del FSLN, fue algo natural. "Además, la mística de sacrificio del Frente Sandinista era muy afín a la mística del sacrificio cristiano" (Baltodano, tomo 3, 405).

Un nuevo marco interpretativo nació de la confluencia del sandinismo con el cristianismo revolucionario, pero fue evocado después de 1979, cuando los cristianos defendían a la revolución: Entre cristianismo y revolución no hay contradicción. El hecho sin precedentes en el caso de Nicaragua, afirma Girard, es que por primera vez los cristianos estaban comprometidos con un proyecto revolucionario real y victorioso en nombre de su fe. Sergio Ramírez, miembro de la Junta de Gobierno, proclamaba, en el primer aniversario de la Revolución Sandinista, en 1980, que el "sandinismo y el cristianismo eran dos aspectos vitales y complementarios de la vida nicaragüense" (HODGES 262). 


\section{Perfil y reclutamiento de activistas del Frente Sandinista}

\section{El perfil de las y los activistas}

Se reconstruye aquí el perfil sociodemográfico de 102 activistas y 19 colaboradores a partir de las entrevistas en profundidad que realizó la comandante guerrillera, Mónica Baltodano, condensadas en 4 tomos del libro Memorias de la lucha sandinista. Se utilizó material autobiográfico escrito por combatientes del FSLN y libros de entrevistas realizadas por otros autores. ${ }^{9}$

Para reconstruir el perfil de los actores se utilizaron tres variables disponibles en las entrevistas: (1) edad en 1979; (2) género; (3) nivel educativo. Los resultados confirman que se trata de activistas del primero y segundo escalón del FSLN que encabezaron la lucha política y militar contra la dictadura. Del total de 102 activistas, 23 componen el alto liderazgo de la revolución,; ${ }^{10}$ los demás, en su casi totalidad, formaron parte del liderazgo en las diferentes regiones del país, sea en el gobierno, organizaciones de masas o partido.

El promedio de edad al triunfo de la revolución era de 26-27 años, por lo tanto, está entre los grupos más jóvenes de los movimientos guerrilleros rurales de América Latina: Cuba (28), Venezuela (30), Guatemala (25-26), Colombia (40), Perú (32) y Bolivia (34) (Wickam-Crowley). Esto muestra que las personas se comprometieron a muy temprana edad y que la sobrevivencia de las mayores fue casi nula.

Respecto al género, los estudios académicos sobre la lucha en Nicaragua mencionan que un 30 por ciento del total de combatientes fueron mujeres (Chinchilla, Moulinex, Randall), ${ }_{11}^{11}$ pero no se presentan datos que confirmen esas estimativas. El análisis de las entrevistas de Baltodano permitió identificar que casi un tercio (28.4 por ciento) fueron mujeres con protagonismo en su participación. A pesar de ello, el género marcó diferencia en el reclutamiento y en las actividades en el movimiento, sobre todo en la primera década. A menudo, en la clandestinidad, las mujeres desempeñaban las tareas domésticas y eran auxiliares en las acciones político-militares, aunque mencionan igualdad con los hombres en el entrenamiento militar.

En la década de 1970, ellas se incorporaron a un ritmo superior al de ellos, y encabezaron actividades políticas y militares. Aun así, su participación fue tímidamente reconocida por el FSLN. Cuando se distinguió con títulos de honor a las personas más destacadas, Baltodano (2010, Tomo I), que recibió el grado de comandante guerrillera, opina que fueron concedidos bajo criterios sexistas únicamente a tres mujeres, cuando existían varias activistas cuyos méritos eran iguales o superiores a los de los hombres. Lo mismo sucedió con el grado de comandante de la revolución concedido a nueve hombres y a ninguna mujer.

Al triunfo de la revolución, el primer y segundo escalón del FSLN era compuesto mayoritariamente por estudiantes universitarios (52.9 por ciento) y de secundaria 
(23.5 por ciento) que abandonaron sus estudios para dedicarse a las actividades políticomilitares. El 15 por ciento tenía educación superior y predominaban los profesores, periodistas y religiosos.

Cabe apuntar el rol que jugó la red de colaboradores del FSLN. “Esa categoría no representaba un estatus inferior al de militante o combatiente, había colaboradores con compromiso y coraje mayores que los de algunos militantes" (Baltodano, tomo 4, 26). La Guardia Nacional no distinguía entre militantes y colaboradores y reprimía violentamente a ambos grupos. De las 19 personas entrevistadas, 13 eran hombres y seis mujeres; el promedio de edad en 1979 era de 34.7 años, más alto que el de los militantes. Y sus ocupaciones eran variadas: artistas, religiosos, profesores, empresarios, periodistas y campesinos.

\section{El reclutamiento de activistas en la teoría de la confrontación política}

La campaña de apoyo a los derechos civiles de los negros en el sur de los Estados Unidos, 1964 Mississipi Freedom Summer, fue la base empírica de McAdam para elaborar su modelo teórico sobre el activismo de alto riesgo. Él parte de la premisa de que participar en formas seguras de activismo aumenta la integración de las personas a las redes de activistas, crea afinidad ideológica con el movimiento, compromiso con una idea militante y receptividad para formas más peligrosas de participación. Este reclutamiento gradual -integración y resocialización- es susceptible de promover el activismo de alto riesgo, que está relacionado a los peligros anticipados de tipo social, físico legal y financiero a que se exponen las personas que se integran a él.

Desde el punto de vista individual, los factores que incidirían en el activismo de alto riesgo serían la identificación profunda con la ideología y los objetivos del movimiento; y la disponibilidad biográfica, concepto que se refiere a la ausencia de obstáculos personales -compromisos familiares y profesionales de tiempo integral-que pueden aumentar los costos y riesgos de participar en un movimiento de ese tipo.

Desde el punto de vista de los vínculos sociales con otros activistas y movimientos, habría cuatro condiciones para la participación (McAdam y Paulsen). Primero, la ocurrencia de una invitación a participar en el movimiento. Segundo, que se establezca un vínculo entre el movimiento y una de sus identidades relevantes de la persona. Tercero, el apoyo a ese vínculo de parte de las personas que promueven esa identidad, o sea, de los activistas del movimiento. Cuarto, que no haya una oposición fuerte de personas de quienes dependen otras identidades relevantes.

Este modelo teórico servirá de guía para analizar el activismo de alto riesgo del FSLN. 


\section{El reclutamiento de activistas en el Frente Sandinista}

En relación con los factores individuales, se encontró que en algo más de la mitad de las entrevistas, Baltodano preguntó qué motivos habían tenido los activistas para integrarse al FSLN. Se recibieron dos tipos de respuestas: a) las que señalan una situación de injusticia y opresión: pobreza, analfabetismo, humillación, corrupción, coerción contra todo intento de organización y movilización, represión política; b) las que expresan valores relevantes como "cumplir con un compromiso social", "vivir la opción por los pobres", "seguir el ejemplo de aquellos que murieron", "sacrificarse por una causa justa", "la honra de morir por los oprimidos", "coherencia entre prédica e práctica", "el combate al egoísmo y la debilidad", "realizar un cambio estructural", y medios para cumplir ese objetivo "la lucha armada es el único camino para derrocar a Somoza".

Ante la situación de injusticia y opresión cuyo único responsable, de acuerdo a los marcos interpretativos del FSLN, eran el gobierno somocista y sus aliados, había que tomar una actitud: organizarse en el FSLN, derrocar al gobierno y cambiar las estructuras. La lucha armada era el único medio, lo que presuponía sacrificio, coherencia, compromiso social con los pobres y oprimidos, vencer el egoísmo y la debilidad. Como escribe Sergio Ramírez, recordando al poeta y héroe sandinista, Leonel Rugama, al FSLN se entraba "bajo el juramento de Patria libre o morir con un sentido de tránsito, de provisionalidad respecto a la propia vida, y para eso se requería una convicción casi religiosa" (Ramírez 42). El sacrificio para abrir las puertas del paraíso para otros, en la tierra. No se llegaría a divisar, ni de lejos, la tierra prometida. Pero había que vivir como los santos.

Es importante hacer notar que, entre los valores mencionados, "el ejemplo de los que sacrificaron" y "coherencia entre valores y práctica" ocupan un lugar muy importante para cristianos y no cristianos. Veamos lo que dice el estudiante de medicina, José Mendieta, del movimiento cristiano: "Creo que fue la práctica de quienes integraron los primeros contingentes, no su prédica, ni los estudios teóricos, a veces alejados de la realidad. Esto fue lo que más influyó" (Baltodano, tomo III, 442). Y lo que dice Hugo Torres, estudiante de derecho: “Qué fuerza más poderosa son los ideales de justicia... Cualquier idea o pensamiento, si no fuera porque los héroes los han hecho carne y sangre dispuestos a ser entregados, no llegarían a tener esa fuerza capaz de arrastrar, tras de ellos, a miles y millones de hombres y mujeres" (Torres).

De acuerdo con el modelo teórico de McAdam, no es suficiente identificarse con los valores del movimiento, hay otro factor individual que facilita el compromiso: la disposición biográfica de los activistas. Se seleccionaron dos variables disponibles en las entrevistas para su examen: La edad en el momento del compromiso con el FSLN y la flexibilidad de tiempo, es decir, tener ocupaciones que no dificulten la participación. Los resultados arrojaron, primero, que más del 84 por ciento tenía entre $16 \mathrm{y}$ 24 años cuando ingresó al FSLN, una proporción cuatro veces más alta que el mismo 
grupo de edad en la pirámide demográfica (19 por ciento), tomando como referencia el año de 1970. Segundo, la ocupación de cerca del 66 por ciento era estudiante, lo que confirma una observación que se reitera en los estudios de movilización: la condición de jóvenes estudiantes facilita el compromiso.

Sin embargo, más del 22 por ciento tenía vínculos de trabajo o de trabajo y estudio y logró trasponer esa barrera biográfica, ya sea porque pudo manejar la situación, o por el convencimiento de la importancia de su compromiso con la misión que se proponía el movimiento. Bayardo Arce, entrevistado por Arias (1985) declara que al recibir la invitación de entrar al Frente, "fui viendo que era factible el poder conjugar las responsabilidades para con mi familia -que era bien pobre- con el trabajo revolucionario". Pero llegó un momento en que era imposible y agrega: "sabía que era más importante la gran familia que la pequeña familia" (63). Esta capacidad de superar las barreras biográficas ya había sido observada en otros estudios. ${ }^{12}$

Los vínculos sociales como la participación en comunidades sociales o políticas, o contactos con amigos y familiares comprometidos con una causa, tienen una función de socialización. La inserción previa de personas en estas redes las ubica en una estructura interactiva que les permite definir y redefinir su marco interpretativo de la vida social antes de su compromiso, y como resultado, aumentan su conciencia política en relación a un tema particular (Passy y Giugni). En el caso de los movimientos clandestinos el reclutamiento depende de un fuerte grado de confianza entre reclutadores y candidatos a militantes o colaboradores, de modo que las posibilidades de incorporación son siempre limitadas (Della Porta).

En el FSLN, más de 3/4 partes de las personas entrevistadas recibieron la invitación para participar de amigos o familiares. En algunos casos los familiares ya eran activistas o colaboradores, en otros, encontraron a amigos en diferentes contextos de reclutamiento (McAdam y Paulsen), o sea, en comunidades/identidades que sirvieron de base para la socialización en los marcos interpretativos del sandinismo y aumento de la consciencia política. ¿En qué contextos o estructuras interactivas el FSLN reclutó a sus activistas y colaboradores?

Como se puede observar en la Tabla 3, los movimientos estudiantiles universitario y de secundaria constituyen el contexto de reclutamiento más importante para el FSLN. Más de un tercio de los entrevistados fueron reclutados en ellos a partir de 1968. La organización en la que más activistas participaron fue el Frente Estudiantil Revolucionario (FER),13 fundado en 1962 por estudiantes de izquierda y que desde 1963 mostraba una clara alineación con el FSLN (Baltodano, tomo I). No obstante, en el IV Congreso de los Estudiantes, en 1969, cuando su plataforma manifiesta claramente apoyo al programa del FSLN demandando la autonomía universitaria, confirmando la violencia organizada como el único método de lograr la independencia del país, contra la oligarquía, la dictadura y el imperialismo. 
Tabla 3

VÍNCULOS PREVIOS DE LAS PERSONAS ACTIVISTAS DEL FRENTE DE LIBERACIÓN NACIONAL (FSLN), NICARAGUA

\begin{tabular}{lcc}
\hline Movimientos & Número & Porcentaje \\
\hline Movimiento estudiantil & 36 & 35.3 \\
Movimiento religioso & 23 & 22.5 \\
Partido político/movimiento político/armado & 18 & 17.6 \\
Movimiento sindical & 3 & 2.9 \\
Ningún vínculo & 20 & 19.6 \\
Sin información & 3 & 2.9 \\
\hline Total & 102 & 100 \\
\hline
\end{tabular}

Fuente: Elaboración propia a partir de Baltonado (2010).

El FER ganó en 1969 las elecciones estudiantiles en el Centro Universitario de la Universidad Nacional (CUUN), el más importante del país, para nunca más perderlas. La participación en el FER permitía a los activistas redefinir el marco interpretativo de su mundo social, familiarizándose con el encuadramiento del sandinismo. Cambió la comunicación con los estudiantes, y el arte pasó a tener un papel importantísimo. La poesía, el teatro y la música llevaban los marcos de las actividades estudiantiles a los movimientos populares (Baltodano, tomo I).

Hubo además dos grupos de estudiantes reclutados en el exterior. Los nicaragüenses de familias ricas que fueron a estudiar a Europa y participaron en las campañas de apoyo a las luchas del Tercer Mundo. Y el grupo reclutado en la Universidad Patrice Lumumba, en Moscú. Miembros de ambos grupos recibieron entrenamiento militar en Palestina.

El segundo contexto de reclutamiento más importante fue el movimiento religioso, ${ }^{14}$ con el 22.5 por ciento de los activistas reclutados. Se incluyeron en este contexto las personas que comenzaron su activismo en los movimientos cristianos, así después hayan participado en el movimiento estudiantil de colegios y universidades. La casi totalidad de los compromisos ocurrió entre 1970 y 1977, y el mayor número de reclutados procede del Movimiento Cristiano Revolucionario (MCR). Como expresó Fernando Cardenal: "La Revolución Popular Sandinista es la primera revolución en la historia de la humanidad que no se hizo a pesar de los cristianos o contra los cristianos, sino con los cristianos, con una profunda participación de éstos" (Baltodano, tomo 1, 353). 
El tercer contexto de reclutamiento está relacionado con la participación en partidos políticos y movimientos políticos y armados, y es bastante heterogéneo. En total, el 17.6 por ciento de las personas entrevistadas tenían lazos previos con partidos y movimientos. Se incluyeron: 1) el Partido Socialista Nicaragüense (PSN) y el Partido Conservador; 2) los movimientos políticos de resistencia civil y armados del ciclo de protestas 1958-1963; 3) los partidos de izquierda en el exterior.

Dada la heterogeneidad del contexto, los reclutamientos tuvieron patrones muy distintos en comparación con el movimiento estudiantil y cristiano. Al PSN habían pertenecido algunos de los fundadores del FSLN que rompieron sus vínculos a raíz del triunfo de la Revolución cubana y se integraron a los movimientos armados y de resistencia civil del ciclo de protestas. También habían sido del PSN algunos miembros de los gremios de zapateros y sastres, además de campesinos que se organizaron en la lucha por derechos sociales y por la tierra. Bases del Partido Conservador esparcidas en el campo y miembros de los movimientos conservadores del ciclo de protestas y sus hijos se pasaron al FSLN.

Del contexto de reclutamiento sindical y asociativo pocos activistas fueron entrevistados. Es probable que estén subrepresentados, sin embargo, es conocido que el nivel de organización asociativa en Nicaragua era pequeño comparado a otros países de América Central. Sindicatos y federaciones de maestros precedieron a organizaciones como AMPRONAC, ATC y otras, fundadas en 1977, pero la represión fue tan violenta ante las movilizaciones por mejores condiciones de trabajado que terminaron destruidos, como le ocurrió a la Federación Sindical de los Maestros de Nicaragua. Además de la represión, hubo el despido masivo de 600 maestros en todo el territorio nacional, y solo consiguieron trabajo cuando triunfó la revolución.

De acuerdo con la Tabla 3, casi el 20 por ciento de las personas entrevistadas no tuvo vínculos con ningún movimiento antes de su ingreso al FSLN. La mayoría absoluta fue reclutada por amigos y familiares, con excepción de algunos casos en que los activistas se aproximaron por cuenta propia. Un tercio de esos activistas declararon que miembros de sus familias eran militantes o colaboradores del FSLN. Otros, fueron reclutados por amigos y pasaron directamente a las actividades de conspiración, sin participar de otros partidos o movimientos, como fue el caso de Glauco Robelo. Su familia era reconocidamente antisomocista en la ciudad de León y él vivía rodeado de activistas, en casa y en el barrio. Recuerda que fue reclutado a los 15 años, por un miembro de la dirección nacional del FSLN que su padre hospedaba. Le enseñó a armar y desarmar armas y le fue pidiendo que cumpliera algunas tareas (Baltodano, tomo III). Después le tomó el juramento que había elaborado Carlos Fonseca y que tenía que recitar cada militante que era reclutado:

Con mi pensamiento y mi corazón puestos en el inmortal ejemplo patriótico de Augusto César Sandino y de Ernesto Che Guevara; ante el recuerdo de todos los héroes y mártires, 
por la liberación de Nicaragua, América Latina y la humanidad entera; ante la historia, pongo mi mano sobre la bandera roja y negra que significa Patria Libre o Morir. Juro defender con las armas en la mano el decoro nacional y combatir por la redención de los oprimidos y de los explotados de Nicaragua y del mundo. Si cumplo este juramento, la liberación de Nicaragua será mi premio; si traiciono este juramento, la muerte oprobiosa y la ignominia serán mi castigo (Borge 245).

\section{Los contextos de reclutamiento y la coyuntura política}

Se encontraron diferencias en el volumen de adhesión al FSLN que parecen explicables por la variabilidad de las coyunturas políticas. El objetivo de este apartado es relacionar las diferentes fases de movilización, el volumen de reclutamiento y la interacción con el gobierno. De acuerdo con las estrategias, uso y combinación de diferentes repertorios, políticas de reclutamiento y efectos de la represión sobre el FSLN, fueron definidas cinco fases en su trayectoria, como puede verse en la Tabla 4.

Tabla 4

AFILIACIÓN DE LAS PERSONAS ENTREVISTADAS AL FRENTE SANDINISTA DE LIBERACIÓN NACIONAL (FSLN), NICARAGUA

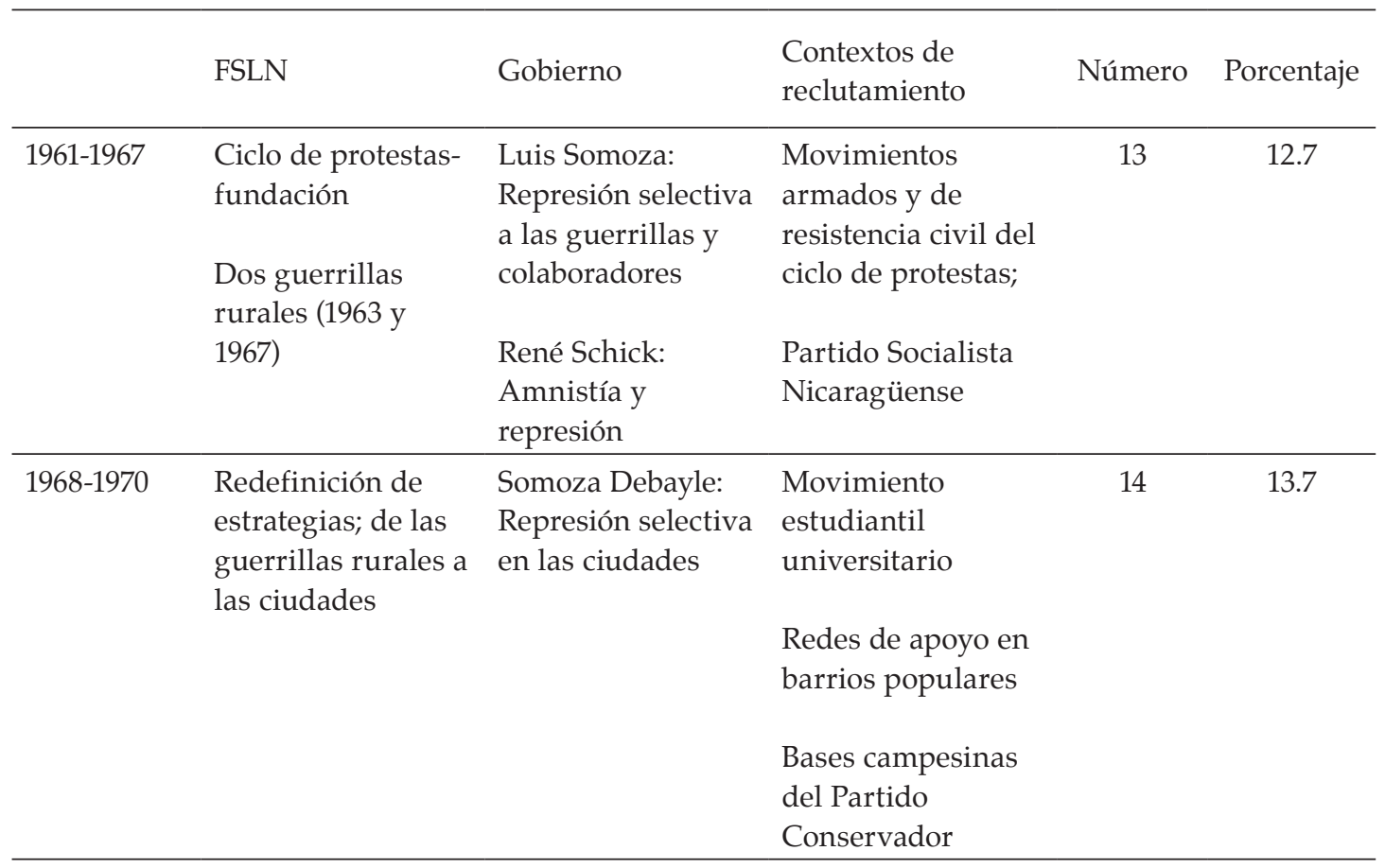

Continúa... 


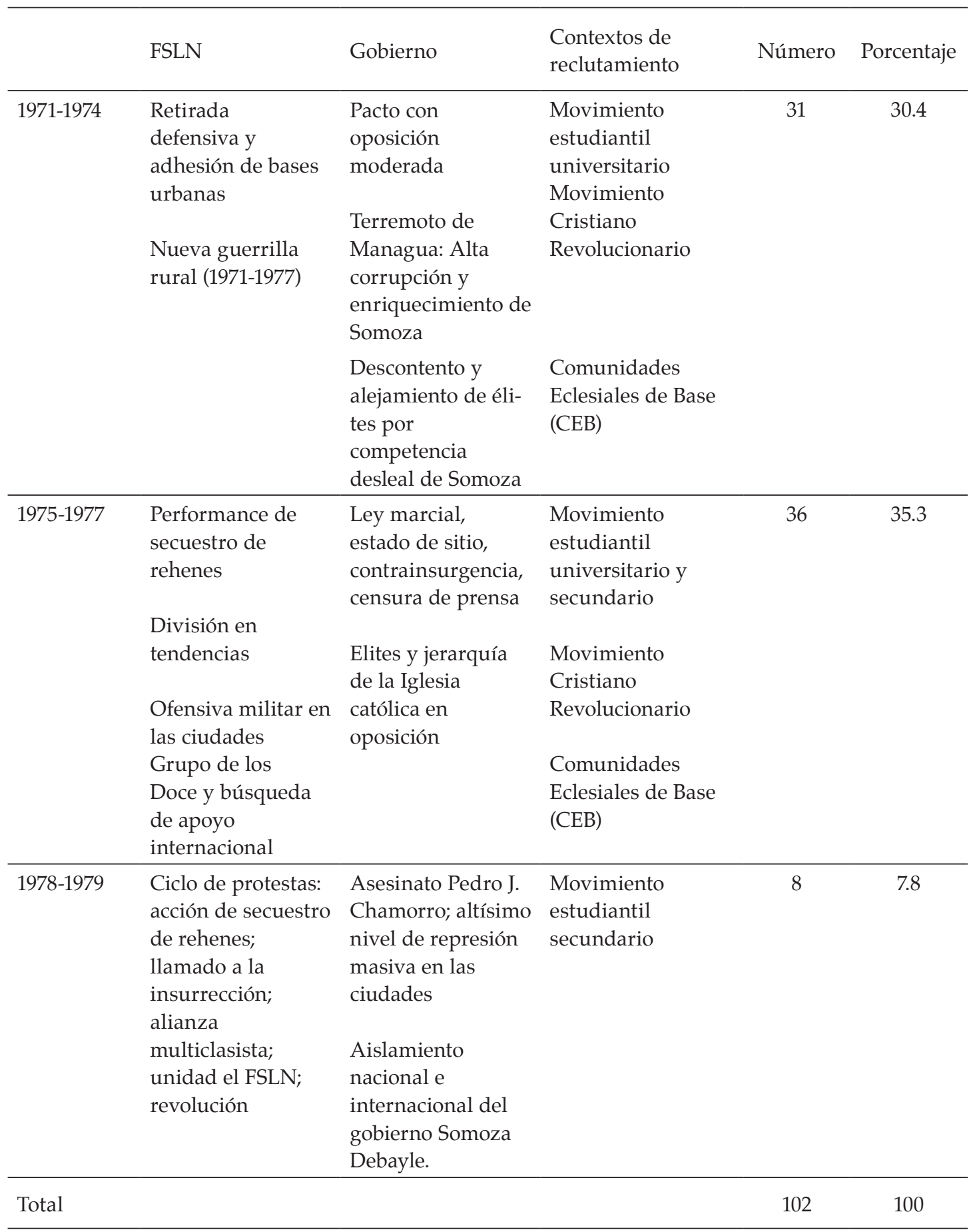

Fuente: Elaboración propia a partir de Baltonado, 2012. 


\section{Fase 1: Las guerrillas rurales (1961-1967)}

Los sandinistas organizaron en este período dos guerrillas en la montaña, RaitíBocay y Pancasán. Su duración fue de apenas algunos meses debido a la falta de apoyo en el campo y a la casi aniquilación de sus miembros por la Guardia Nacional. En la práctica, este período no dio lugar a grandes avances en el reclutamiento de activistas (12.7 por ciento). Como se ha mencionado, los contextos principales de reclutamiento fueron los movimientos armados y de resistencia civil que se desarrollaron durante el ciclo de protestas y el Partido Socialista Nicaragüense de donde provenían algunos de los fundadores del FSLN.

\section{Fase 2: De la guerrilla rural a las ciudades (1968-1970)}

La última derrota de la guerrilla obligó a los líderes del FSLN a replantear sus estrategias. Carlos Fonseca lanzó el programa y estatutos además de confirmar la lucha armada como performance central del derrocamiento de la dictadura. Consideró que la lucha armada no podía tener éxito sin la conexión con un poderoso movimiento popular. A partir de 1969, el principal contexto de reclutamiento se desplazó hacia el movimiento estudiantil y el FER se convirtió en su base organizativa y social. Fue un trampolín de activistas para el FSLN. Sin embargo, activistas remanecientes de las guerrillas lograron reclutar a familias campesinas de las bases del Partido Conservador. Aun así, un total de 13.7 por ciento de activistas se comprometieron.

\section{Fase 3: Retirada defensiva y recomposición de las bases urbanas y rurales (1971-1974)}

En respuesta a la violenta represión, el FSLN decidió entrar en un período llamado de "acumulación de fuerzas en silencio". La orientación era no ofrecer combate, salvo en casos de extrema necesidad. El objetivo era llevar a cabo un trabajo político-organizativo para fortalecer el movimiento, a partir de: desarrollo de las organizaciones intermediarias - puentes entre el movimiento popular y el movimiento revolucionario-; creación de vínculos con sectores potencialmente revolucionarios como los movimientos cristianos inspirados en la teología de la liberación; y formación de redes de apoyo en los barrios. La guerrilla fue reanudada en la montaña y activistas del movimiento estudiantil y movimiento cristiano la nutrían.

Estos años fueron muy fructíferos para el FSLN en términos de reclutamiento. El 30.4 por ciento de las personas entrevistadas por Baltodano se comprometieron en sus actividades, un poco más de la mitad de ese porcentaje estaba compuesto por mujeres. Los contextos de reclutamiento más importantes fueron el movimiento estudiantil y el movimiento cristiano. El FSLN se fortaleció con el apoyo de las redes de las Comunidades Eclesiales de Base (CEB) en las principales ciudades del país. 
De este contexto surgirán líderes, activistas del movimiento popular, una amplia red de apoyo (Baltodano, 2010, volumen I) y nuevas performances como la ocupación de iglesias y colegios.

\section{Fase 4: División del FSLN en tres tendencias/Ofensiva militar (1975-1977)}

La cuarta fase del proceso político se inició a fines de 1974 con el asalto a la casa de Chema Castillo, una de las performances más audaces del FSLN: secuestro de rehenes del gabinete de Somoza. La acción logró su principal objetivo -alcanzar notoriedad y además comunicar que era capaz de asestar un golpe de esa envergadura-. La respuesta del gobierno no se hizo esperar: decretó la ley marcial, el estado de emergencia, censura de prensa y reprimió fuertemente a activistas, colaboradores y sospechosos de brindar apoyo al FSLN.

Entre febrero de 1975 y noviembre de 1976, surgen contradicciones dentro del FSLN que resultan en su división en tres tendencias: Guerra Popular Prolongada (FSLNGPP); Tendencia Proletaria (FSLN-TP) y Tercerista o Insurreccionalista (FSLN-TT). Las tres incluyeron el nombre FSLN en sus grupos y la principal razón del fraccionamiento, de acuerdo a los entrevistados, decía respecto a diferencias en la estrategia para derrocar a Somoza Debayle. En segundo plano se ventila una rivalidad entre dirigentes. En noviembre de 1976, Carlos Fonseca se trasladó de Cuba a Nicaragua para tratar de unir al universo sandinista, pero murió en un enfrentamiento con la Guardia Nacional en la montaña antes de lograr su cometido.

La muerte del gran líder impactó profundamente a los activistas. Sin embargo, las tendencias del FSLN pusieron en práctica sus estrategias y continuaron reclutando partidarios. Durante este período, se comprometió con el activismo de alto riesgo el 35.3 por ciento de las personas entrevistadas, el porcentaje más alto de todas las fases. También se destaca la alta participación femenina, alrededor de la mitad de este total. Las entrevistas revelan que las personas se alineaban con las tendencias de acuerdo a relaciones personales, lo que sugiere que la derrocada de Somoza era el elemento clave para el reclutamiento, no importaba si la estrategia política eran las acciones armadas urbanas o la organización de asociaciones laborales o de mujeres.

\section{Fase 5: Ciclo de protestas: llamado a la insurrección y la revolución (1978-1979)}

En enero de 1978, se inició un nuevo ciclo de protestas que disparó a partir del asesinato del periodista Pedro Joaquín Chamorro, y llegó a su ápice en julio de 1979 con el triunfo de la revolución. El nacimiento y la activación de las organizaciones de masas fueron, en gran parte, resultado de la acción de la militancia sandinista, con el objetivo de articular grupos de apoyo general a la lucha armada. La Asociación de los Trabajadores del Campo (ATC), los Comités de Defensa Civil (CDC), la Asociación de Mujeres Frente a la Problemática Nacional (AMPRONAC). 
La Tendencia Tercerista del FSLN organizó una performance en los moldes de la acción de 1974, pero de dimensiones superiores. Un comando sandinista ocupó el edificio del Palacio Nacional, sede del Congreso Nacional. Entre los rehenes había varios parientes de Somoza. Manifiestos y comunicados de guerra fueron leídos en las radios y publicados en la prensa escrita. Cincuenta y dos activistas presos fueron liberados, y el comando recibió medio millón de dólares. Esto produjo más desgaste para el gobierno y más prestigio para el FSLN.

La reunificación del Frente Sandinista en marzo de 1979, la masiva participación en la insurrección final producto sobre todo de la violenta represión, el deterioro de la situación nacional e internacional del gobierno de Somoza y la formación de una alianza multiclasista favorecieron el desenlace final. Como se muestra en la Tabla 3, hay pocas personas reclutadas en este período, menos del 8 por ciento, y la mayoría provienen del movimiento de estudiantes de secundaria. A esa altura, ya el liderazgo de la revolución se había formado en el largo período de experiencia política y militar.

\section{Conclusiones}

Se presentaron los antecedentes políticos del activismo de alto riesgo sandinista. Las oportunidades políticas que se abrieron en 1958 fueron creadas por un grupo de opositores que asesinaron a Somoza García, con lo cual se desencadenó un ciclo de protestas. La represión indiscriminada y la continuidad de la familia Somoza en el gobierno produjo una coyuntura facilitadora de cierto tipo de movilización: el movimiento armado, que se difundió rápidamente.

Los opositores exiliados en los países vecinos fueron los primeros en organizar por lo menos una decena de movimientos armados que incursionaron en el país. En esa coyuntura, se constituyó otro relevante actor colectivo, el movimiento estudiantil que enfrentó al gobierno en manifestaciones callejeras, y provoco la aparición de por lo menos siete movimientos de resistencia civil que acogieron a jóvenes estudiantes y a algunos trabajadores.

También en la fase de conflicto y difusión surgió un nuevo tipo de oposición que no desbancó a la oposición moderada al régimen somocista pero que empezó a perfilarse. Una generación más joven, más radical, que se identificaba con la Revolución Cubana, con la campaña nacionalista y antiimperialista de Sandino y con un programa de libertades democráticas.

En ese cambio generacional del perfil de los movilizados se constituyó también un nuevo liderazgo. Los jóvenes activistas movilizados encontraron en Carlos Fonseca un líder observador y estudioso de la experiencia nacional e internacional, audaz, persistente y convencido de la victoria. Fonseca, con "paciente impaciencia" (Borge) fue guiando al grupo en la construcción del movimiento sandinista. 
El repertorio de confrontación -lucha armada- fue escogido por el FSLN como su estrategia principal. Esta configuración política generó las condiciones para la emergencia de un activismo de alto riesgo, secundado por un activismo de performances no violentas.

Se observó que Fonseca reunía en su carrera política dos atributos como líder: capacidad de organización de recursos humanos y materiales y carisma. Fue el responsable por el proceso de construcción del marco interpretativo sandinismo que guio la movilización contra la dictadura. Lo hizo a partir de otros dos marcos: los valores morales y símbolos nacionalistas y antiimperialistas de Sandino, y el marxismo revolucionario del Che Guevara.

El diagnóstico de la situación del país apuntaba a un cuadro de injusticia, provocado por la opresión de la dinastía somocista, apoyada por el gobierno norteamericano; y la estrategia para vencer era construir un movimiento revolucionario cuya meta era la toma del poder y la concreción de cambios políticos, sociales y económicos en el país. Carlos Fonseca enmarcó la realidad en la consigna ¡Patria Libre o Morir! Y como símbolo escogió la bandera rubro-negra usada por Sandino, con la inscripción FSLN.

Fue de fundamental importancia para la actividad insurgente la incorporación al FSLN de los cristianos identificados con la teología de la liberación. Los valores sandinistas y cristianos eran similares y evocaban el sacrificio, la coherencia entre valores y práctica y el ejemplo.

El análisis de las carreras de los activistas permitió identificar que se trataba de un grupo líder del FSLN. De los entrevistados, más del 20 por ciento recibieron títulos de honor por su destacada participación en el combate a la dictadura.

El promedio de edad al triunfo de la Revolución Sandinista fue de 26-27 años, uno de los liderazgos más jóvenes entre los movimientos guerrilleros rurales latinoamericanos. Estudiantes universitarios (52.9 por ciento) y estudiantes secundarios (20.6 por ciento) sumaron cerca de tres cuartos del total de activistas entrevistados.

Casi un tercio del total fueron mujeres, confirmando las afirmaciones sobre la alta participación femenina en el combate sandinista a la dictadura. En los 70 el ritmo de la incorporación al FSLN fue mayor que el de los hombres.

Entre los factores individuales que facilitan el compromiso de los activistas están las medidas de disponibilidad biográfica, personas libres de compromisos familiares y responsabilidades de empleo. En el caso nicaragüense, el contexto estudiantil mencionado anteriormente está relacionado positivamente con franjas de edad bajas y alta disponibilidad de tiempo. El resultado revela que más del 84 por ciento de las personas estaba en el grupo de edad de 16 a 24 años en el momento de su reclutamiento. La ocupación "estudiante" de la mayoría (62 por ciento) y su juventud la predispuso para el compromiso. Se encontró, sin embargo, un grupo de más del 22 por ciento que tenía deberes, sobre todo familiares, que cumplir y lograron superar los obstáculos. Esto ya había sido observado por estudiosos de otros movimientos y 
el manejo de la situación se atribuye a la importancia que el compromiso militante tenía para esas personas.

Otro factor individual es una fuerte identificación con las ideas y valores del movimiento. Los motivos citados por los activistas muestran una concordancia general con los marcos interpretativos construidos por los líderes del FSLN. Pero, en el activismo de alto riesgo no siempre es así. Relatos de jóvenes nicaragüenses que se incorporaron en el último tramo de la insurrección final, de forma masiva, señalan a la represión somocista como el factor desencadenador de su activismo. Viterna también encontró que el modelo de McAdam no considera la violencia del Estado, y en el caso de países con regímenes dictatoriales, esa variable debe ser tomada en cuenta en la ecuación del activismo de alto riesgo. En su análisis de las mujeres campesinas, el camino de su incorporación al FMLN varió de acuerdo con el tipo de represión, si indiscriminada o dirigida a los activistas.

Respecto a los vínculos sociales, que pueden inhibir como promover el activismo, en el caso aquí estudiado, los vínculos sociales fuertes -familiares y amigosfueron de gran importancia para la movilización de alto riesgo: el 77.5 por ciento de las personas entrevistadas fueron reclutadas por reclutadores con quienes mantenían ese tipo de vínculo.

Además, el compromiso previo en organizaciones sociales facilita el reclutamiento, pues esas organizaciones van paulatinamente socializando a los individuos en la carrera de activista. En consonancia con esa perspectiva, se reconstruyeron los contextos de reclutamiento -comunidades/identidades que podrían facilitar o inhibir el activismo de alto riesgo- que dieron origen al activismo sandinista.

Dos de esos contextos empujaron a los activistas al compromiso con el movimiento clandestino FSLN: el movimiento estudiantil y el movimiento religioso, que capturaron el 57.8 por ciento de las personas comprometidas. Otro contexto importante fue el de los partidos y movimientos políticos, más efectivo en la primera década del movimiento, ya que la mayoría de sus fundadores y primeros activistas salieron de ese contexto. A pesar de su heterogeneidad, partidos y movimientos con diferentes marcos interpretativos y repertorios movilizaron el 17.6 por ciento de los activistas.

El modelo de McAdam no tiene en cuenta el impacto, en términos de volumen y forma, de las coyunturas políticas en los procesos de reclutamiento. Para entender cuáles fueron esos impactos, se hizo un esfuerzo para dividir el movimiento en cinco fases, correlacionando las estrategias de acción política y los repertorios de enfrentamiento adoptados en respuesta a la represión de las autoridades. Los dos períodos de mayor reclutamiento de las personas entrevistadas fueron 1971-1974 (30.4 por ciento) y 1975-1977 (35.3 por ciento). En ellas hubo una combinación del repertorio violento con un repertorio no violento: las guerrillas en las montañas con la formación de redes de campesinos de abastecimiento e información; y las actuaciones violentas puntuales en las ciudades, combinadas con las agendas reivindicatorias y conectadas a la 
política nacional del movimiento estudiantil y religioso y de las comunidades pobres en las ciudades.

Más allá de los datos, cabe destacar aquí la riqueza de los testimonios de los activistas del Frente Sandinista, que manifestaron sus sentimientos de amistad y admiración por sus reclutadores, y cómo esos sentimientos los "llamaban a cumplir el deber", enfrentando y superando las barreras del miedo a las torturas y de la muerte. También destacan que el FSLN se convirtió a lo largo del tiempo en el único movimiento admirado por su capacidad de enfrentamiento al régimen somocista y por la disposición al sacrificio de sus activistas. Muchos cristianos reflexionaban sobre esta disposición, incidiendo en su decisión de participar hasta las últimas consecuencias, en nombre de la fe. Finalmente, la figura central del líder Carlos Fonseca, con sus atributos reales o sobrenaturales, ejerció ciertamente un rol fundamental en el compromiso de todos.

\section{Notas}

1 Este artículo se elaboró a partir de la disertación de maestría de la autora: Salgado, María Mercedes. Recrutamento em movimentos de alto risco: o caso da Frente Sandinista de Libertação Nacional da Nicarágua. Dissertação (Mestrado em Sociologia). 179 f. Universidade de São Paulo, 2016.

2 En la literatura de la confrontación política, los movimientos son de alto riesgo por los peligros anticipados de tipo social, físico, legal y financiero a los que están expuestas las personas que en ellos se comprometen, así como de alto costo por el tiempo y la energía invertidos en el activismo (McAdam).

Las oportunidades son dimensiones consistentes de la lucha política que alientan la confrontación, mientras que las amenazas políticas son factores que plantean barreras sólidas a los insurgentes y desalientan el enfrentamiento (Tarrow).

Tilly (2003) afirma que los desafiadores muestran a las autoridades su insatisfacción en el espacio público a través de performances interactivas que siguen un guion poco definido: ensayan peticiones, manifestaciones, levantes urbanos, secuestros de rehenes $\mathrm{u}$ otras formas de confrontación. El repertorio de confrontación es ese "conjunto limitado, familiar, históricamente creado de performances reivindicativas que circunscriben en mucho los medios a través de los cuales las personas se involucran en enfrentamientos políticos" (Tilly vii, apud Alonso 36).

Augusto C. Sandino organizó y dirigió la resistencia armada de 1927 a 1933 y fue fusilado en 1934 por la Guarda Nacional, cuyo director era el general Anastasio Somoza García.

Lowy, M. (1982). El marxismo en América Latina: [De 1909 a nuestros días]; Antología. México: Era; Castañeda, J. G. (1993). La utopía desarmada. Intrigas, dilemas y promesa de la izquierda en América Latina. Bs. As.: Ariel; Pereyra, D. (2000). Del Moncada a Chiapas. Historia de la lucha armada en América Latina. La Rioja, Argentina: Canguro; Gaspar, G. (1997). Guerrillas en América Latina. Chile: FLACSO; Wright, T. C. (2001). Latin America in the Era of the Cuban Revolution. Greenwood Publishing Group. 
7 Primero, proporcionó un diagrama claro de cómo hacer una insurrección victoriosa con el manual de la guerra de guerrillas del Che Guevara. Segundo, Cuba fue el único país que realizó transformaciones sociales completas y cortó la dominación de Estados Unidos. Tercero, tuvo un líder dinámico y carismático que simbolizó la revolución y conquistó la simpatía popular a lo largo del hemisferio, promoviendo la insurrección contra gobiernos establecidos y la burguesía en América Latina. Finalmente, la Revolución Cubana debe mucho de su influencia al desarrollo de los medios y las habilidades de comunicador de Fidel Castro.

Dussel destaca que el "núcleo duro" de las ideas de la teología de la liberación podría resumirse en la siguiente tesis: "se trata de una teología que parte del discurso de una opción ética por los pobres, la construcción práctica aquí y ahora del Reino de Dios" (203). Dussel, Enrique. "Teología de la Liberación. Transformaciones de los supuestos epistemológicos". Theologica Xaveriana No. 47, 1997, p. 203-214. Más detalles en Morlina, Fabio. “Teologia da Libertação na Nicarágua Sandinista" 222 f. Dissertação (Mestrado em História Social). Universidade de São Paulo, 2009.

$9 \quad$ Borge Martínez, Tomás. La paciente impaciencia. La Habana: Casas de las Américas, 1989; Cabezas, Omar. La montaña es algo más que una inmensa estepa verde. 3. ${ }^{a}$ ed. Managua: Nueva Nicaragua, 1985; Ramírez, Sergio. La marca del Zorro: Hazañas contadas por el comandante Francisco Rivera Quintero a Sergio Ramírez. 2a. ed. Managua: Nueva Nicaragua, 1999; Randall, Margaret. Cristianos en la revolución. Managua: Nueva Nicaragua, 1983 y Estamos todas despertas. São Paulo: Global Editora, 1982; Torres, Hugo. Rumbo norte. Historia de un sobreviviente. Managua: Editorial Hispamer, 2a. ed., 2003; Arias, Pilar. Nicaragua: revolución. 4. ${ }^{a}$ ed. México: Siglo XXI, 1985.

Cinco comandantes de la revolución, tres comandantes guerrilleras y 15 comandantes guerrilleros.

11 Chinchilla, Norma. "Revolutionary Popular Feminism in Nicaragua: Articulating Class, Gender, and National Sovereignty". Gender and Society, 1990; Molyneux, Maxine. "Mobilization without Emancipation? Women's Interests, the State, and Revolution in Nicaragua". Feminist Studies, 1985; Randall, Margaret. Estamos todas despertas, 1982.

Nepstad, Sharon Erickson; Christian Smith. "Rethinking recruitment to high-risk/cost activism: The case of Nicaragua Exchange". Mobilization: An International Quarterly, v. 4, n. 1, 1999, p. 25-40; Viterna, Jocelyn. "Pulled, pushed, and persuaded: Explaining Woman's mobilization into the Salvadorian guerrilla army". American Journal of Sociology, 112.1 (2006): 1-45.

13 Otros: el Movimiento de Estudiantes de Secundaria (MES), que en algunas regiones se llamaba Asociación de Estudiantes de Secundaria (AES); algunos mencionan a la Organización de Estudiantes de Secundaria (OES) del Colegio Centroamérica, colegio privado jesuita; 4) el Centro Estudiantil Ramírez Goyena (CERG), instituto público de secundaria.

Incluye: 1) el Movimiento Cristiano Revolucionario (MCR); 2) el Movimiento Estudiantil Cristiano (MEC); 3) los Delegados de la Palabra de Dios; 4) la Juventud Universitaria Católica (JUC); 5) la Acción Católica (AC); la Juventud Franciscana (JUFRA).

\section{Bibliografía}

Alonso, Angela. "Repertório, segundo Charles Tilly: história de um conceito". Sociologia EAntropologia, 02 (03), 2012: 21-41. 
Aminzade, Ronald y McAdam, Doug. "Emotions and Contentions Politics". En Aminzade, Ronald et al. (Eds.). Silence and Voice in the study of contentious politics. Cambridge University Press, 2001.

Baltodano, Mónica. Memorias de la lucha sandinista. Managua: Fundación Rosa Luxemburgo, volúmenes 1, 2 y 3, 2010.

Baltodano, Mónica. Memorias de la lucha sandinista. Managua: Fundación Rosa Luxemburgo, volumen 4, 2012.

Benford, Robert D. y Snow, David A. "Framing Processes and Social Movements: An Overview and Assessment". Annual Review of Sociology, 26, 2000, 611-639.

Blandón, Miguel de Jesús. Entre Sandino y Fonseca Amador. 2.a ed. Managua: Impresiones y Troqueles, 1980.

Borge Martínez, Tomás. Carlos, el amanecer ya no es una tentación. Managua: Nueva Nicaragua, 1982.

Borge Martínez. La paciente impaciencia. La Habana: Casas de las Américas, 1989.

Della Porta, Donatella. "Recruitment processes in clandestine political organizations: Italian left-wing terrorism". International Social Movement Research, 1: 155-169, 1988.

Fonseca, Carlos. Bajo la bandera del Sandinismo. Prefacio de Humberto Ortega Saavedra. 3. ${ }^{\text {a }}$ ed. Managua: Nueva Nicaragua. IES, 1985.

Fonseca, Carlos. Viva Sandino. Prefacio de Jaime Wheelock Román. 2. ${ }^{\text {a }}$ ed. Managua: Nueva Nicaragua. IES, 1985.

Girardi, Giulio. Sandinismo, marxismo, cristianismo en la nueva Nicaragua. Centro Ecuménico Antonio Valdivieso. México: Ediciones Nuevomar, S. A. de C.V., 1986.

Girardi, Giulio. Fe en la revolución, revolución en la cultura. Managua: Nueva Nicaragua, Monimbó, 1983.

Goodwin, J. (2005). "Revolutionary Movements in Central America: A Comparative Analysis". En Hall, John A. (Ed.). The state: critical concepts. Volume III. Routledge.

Hodges, Donald C. Intellectual foundations of the Nicaraguan revolution. University of Texas Press, 1986.

Kinloch Tijerino, Frances. Historia de Nicaragua. Managua: IHNCA-UCA, 2005.

McAdam, Dough. "Recruitment to High-Risk Activism: The Case of Freedom Summer". American Journal of Sociology, 92, 1, 1986: 64-90.

McAdam, Doug. "'Initiator' and 'Spin-off' Movements: Diffusion Processes in Protest Cycles”. En Mark (Ed.), Repertoires and Cycles of Collective Action by Traugott. Duke University Press: Durham, 1995.

McAdam, Doug y Paulsen, Ronnelle. "Specifying the Relationship between Social Ties and Activism". American Journal of Sociology, 99, 3, 1993: 640-667.

McAdam, Doug. "Pour dépasser l'analyse structurale de l'engagement militant". En Fillieule, O. (Org.) Le désengagement militant. París: Editions Belin, 2005.

McAdam, Doug; Tarrow, Sidney; Tilly, Charles. Dynamics of Contention. Cambridge University Press, 2001.

Passy, Florence; Giugni, Marco. “Social Networks and Individual Perceptions: Explaining Differential Participation in Social Movements". Sociological Forum, 16. 1 (2001): 123-153.

Ramírez, Sergio. El pensamiento vivo de Sandino. Managua: Nueva Nicaragua, 1981. 
Ramírez, Sergio. Adiós muchachos. Una memoria de la revolución sandinista. San José: Santillana, 1999.

Snow, David y Benson, Robert D. "Ideology, frame resonance and participant mobilization". International Social Movement Research, 1, 1988: 197-217.

Tarrow, Sidney. El poder en movimiento. Los movimientos sociales, la acción colectiva y la política. Alianza Editorial, S. A., Madrid, 1994.

Tirado López, Víctor. Nicaragua: una nueva democracia en el Tercer Mundo. Managua: Editorial Vanguardia, 1986.

Torres-Rivas, E. (1997). “Centroamérica revoluciones sin cambio revolucionario". Nueva Sociedad, 150, 84-89.

Viterna, Jocelyn. "Pulled, pushed, and persuaded: Explaining Woman's mobilization into the Salvadorian guerrilla army". American Journal of Sociology, 112 (1): 1-45, 2006.

Wickham-Crowley, Timothy P. Guerrillas and revolution in Latin America: A comparative study of insurgents and regimes since 1956. Princeton University Press, 1992.

Zimmermann, Matilde. Carlos Fonseca e a revolução nicaraguense. São Paulo: Expressão Popular, 2012.

María Mercedes Salgado. Nicaragüense y brasileña. Graduada en Ciencias Sociales (2008) y Máster en Sociología (2016) por la Universidad de São Paulo (USP), actualmente sigue el programa de Doctorado en Sociología de esa casa de estudios. Se ha dedicado a estudiar el tema del activismo político de alto riesgo en Nicaragua y Centroamérica, en perspectiva comparada. En la actualidad es socia directora de la empresa Expertise Social, la cual trabaja con gestión de la información, monitoreo y evaluación de políticas públicas, programas y proyectos sociales. Fue fundadora y directora de proyectos y finanzas de la ONG, Agenda Pública, dedicada a contribuir a la mejoría de las políticas públicas en ámbito municipal en Brasil. En su trayectoria profesional trabajó en el Instituto Nicaragüense de Turismo como asesora del gabinete del Ministro y fungió como diplomática con el cargo de Consejero con Funciones Consulares en la Embajada de Nicaragua en Brasil.

Contacto:mmsraz@hotmail.com

ORCID: 0000-0001-7212-0368 